\title{
The generalized constitutive law in nonlinear structural analysis of steel frames
}

\author{
D. Mrówczyński \\ R\&D Department, FEMat sp. z o.o., Poznań, Poland
}

\author{
T. Gajewski \\ Institute of Structural Analysis, Poznan University of Technology, Poznań, Poland \\ T. Garbowski \\ Department of Biosystems Engineering, Poznan University of Life Sciences, Poznań, Poland
}

\begin{abstract}
The article presents a modified finite element (FE) based algorithm for nonlinear analysis of 2D beam structures, which takes into account the influence of the shear forces. The method proposed enables using complex materials with nonlinearities without the need of implementing advanced constitutive models in FE routines. It can be directly integrated with commonly available FE software for linear analysis of beam structures, so its functionality can be easily extended also with material nonlinearities. The presented approach adopts the generalized constitutive law algorithm to iteratively modify the stiffness of beam element. To address an influence of a shear stiffness, a Timoshenko beam element was used. The methodology was implemented and its performance was verified on several numerical examples. For validation, the displacements and the ultimate loads were compared with the values from a commercial FE software. The results shown a good correlation between the reference model and the method proposed.
\end{abstract}

\section{INTRODUCTION}

For decades an advanced engineering problems are effectively modelled by finite element (FE) method, which is very popular due to its versatility and accuracy. The FE models are often implemented in various modern engineering tools, in comparison to the analytical ones they have wider applicability and universality. Most civil structures can be analysed using simple 2D beam or frame structures without sacrificing the accuracy of the results obtained with simplified models. Thus, majority of commercial software for FE analyses of civil structures use the beam, truss or frame finite elements only. Nowadays, the developers of engineering software often provide their users a functions extending its capabilities with new features. For instance, the users may include new material or element subroutines, which are tailored for their particular needs; this trend may be observed in many top engineering softwares. In such cases, a numerical and material mechanics expertise is required, in order to extend the mechanical models with nonlinear (material or geometric) features through user subroutines. An attractive alternative may be the use of classic beams and frames finite element method (FEM) with linear solver extended with a generalized nonlinear constitutive law (GNCL) algorithm, which is simple and easy to implement. 
This idea appeared in the 70s of the 20th century. One of the first papers which introduced the idea of dividing a cross-section into layers was the analysis of the behaviour of bending composite beams by Rotter \& Ansourian presented in 1978. The theoretical values were compared with the experimental results, a good correlation was obtained. In 1982, Lodygowski applied the method of the generalized nonlinear constitutive law (GNCL) to the geometric and physical nonlinear analysis of beams and plane frames. Later, Lodygowski \& Szumigała applied the division into layers in a two-stage bending analysis of composite beams. In the first stage of the method, the cross-section is discretized, and the constitutive law is formulated as the bending moment-curvature relationship. In the second stage, the constitutive law is adopted in the nonlinear finite element code. The two-stage approach was also used by Szumigała in 2007 to analyse composite steel-concrete frame structures. The constitutive law was formulated in the form of the bending stiffness-curvature relationship. In 2019, Grzeszykowski \& Szmigiera used the GNCL method to compute the nonlinear longitudinal shear distribution in composite steel-concrete beams. The GNCL algorithm was described in more detail by Mrówczyński et al. in 2021, where its performance in steel and composite beam structures was presented.

From a practical point of view, the method is a promising alternative to be used by the structural engineers. The method proposed here extends its original version by including a shear effect. It is easy to use, if one would like to consider in modelling not only complex material/geometrical nonlinearities, but also the shear effect, thus, it may be utilized, instead of building a complex FEM models.

\section{METHODS AND MATERIALS}

\subsection{Normal and shear strains}

The classical framework of FE analysis was used to embed the method proposed. In the small strains and deformations framework, the beam and frame FE was implemented; it may be loaded with an external forces and/or displacements. The nodal displacements are computed in iterations, since the method presented iteratively changes the flexural and shear element stiffness.

The global stiffness matrix is assembled in the classical way by including the stiffness matrices of all elements. In the method proposed, due to deformations the element stiffness is iteratively decreased in the loop. Deformations, namely, $\varepsilon_{0}$ - normal strains, $\gamma$ - shear strains and $\kappa$-curvature, are computed from the nodal displacements $d$. Normal strain, $\varepsilon_{0}$ is taken in the following form:

$$
\varepsilon_{0}=\frac{\Delta l}{l}=\frac{u_{2}-u_{1}}{l}
$$

where $l$ is the beam length, $\Delta l$ is its elongation and $u_{1}, u_{2}$ are the nodal displacements along the beam axis.

Shear strains, $\gamma$, are taken as the difference between the nodal rotation $\varphi$ and the first derivative of vertical deflection, $v$, according to Timoshenko theory:

$$
\gamma=\varphi-\frac{\mathrm{d} v}{\mathrm{~d} x}
$$

Bernoulli theory is also considered in the paper, in order to compare its results with the one including Timoshenko theory. According to Bernoulli's hypothesis the crosssection is perpendicular to the axis of the deformed beam. As the consequence, the shear strains, $\gamma$, equals zero. 
The curvature, $\kappa$, in small displacements, is calculated as the second derivative of a deflection in a vertical direction:

$$
\kappa=\frac{\mathrm{d}^{2} v}{\mathrm{~d} x^{2}}
$$

\subsection{Stiffness reduction}

Element deformations, namely $\varepsilon_{0}, \gamma$, and $\kappa$ - shown in the previous subsection, serves to calculate the element stiffness reduction. For each layer, a location, height, width and crosssectional area of individual material are determined. The procedure is repeated for materials and layers obtained from a cross-section division.

Further, the reduced (effective) strains, $\varepsilon_{r e d}$, are calculated by utilizing the normal and shear strains. Next, in each layer the reduced stress, $\sigma_{\text {red }}$, is derived from the reduced strain by using $\sigma_{r e d}$ vs. $\varepsilon_{r e d}$ plot, which is determined for each material used, if multi-material cross-section is analysed.

Later, from the stresses and strains the Young's modulus, $E$, is calculated. The shear modulus for isotropic materials, $G$, may be classically taken as:

$$
G=\frac{E}{2(1+\nu)}
$$

where $\nu$ is Poisson's ratio. Young's and shear modulus allows to compute the tensile and shear stiffnesses, $B_{N}$ and $B_{V}$, respectively:

$$
B_{N}=\sum_{j=1}^{m} \sum_{i=1}^{n} E_{i}^{j} A_{i}^{j}, B_{V}=\sum_{j=1}^{m}\left(\sum_{i=1}^{n} G_{i}^{j} A_{i}^{j}\right) / k^{j},
$$

where $i$ and $j$ are the layers in the cross section and materials, respectively; $n$ and $m$ are the total number of layers and number of materials, respectively. $A_{i}{ }^{j}$ is area of a cross-section of $i$-th layer and $j$-th material, and $k^{j}$ is a shear correction factor for $j$-th material.

A position of neutral axis $y_{g}$ is computed from:

$$
y_{g}=\frac{\sum_{j=1}^{m} \sum_{i=1}^{n} E_{l}^{j} A_{i}^{j} y_{i}}{E A} .
$$

From the position of the neutral axis, a moment of inertia of $i$-th layer, $I_{i}^{j}$, may be determined; then a bending stiffness, $B_{M}$, may be computed according to the formula:

$$
B_{M}=\sum_{j=1}^{m} \sum_{i=1}^{n} E_{i}^{j} I_{i}^{j}
$$

In the original method, the computations for cross-section are performed before the main algorithm. The law $B_{M} \quad \kappa$ is only computed for the normal forces assumed. The element stiffness values is determined by interpolation of in-between values, thus, the accuracy depends on a prior mesh density assumed. Due to this feature of the original method, an additional 
Table 1. Material parameters of steel used in the study.

\begin{tabular}{|c|c|c|c|c|}
\hline & $E$ & $G$ & $\nu$ & $f_{y}$ \\
\hline Material & [GPa] & [GPa] & {$[-]$} & [MPa] \\
\hline steel & 210.0 & 81.0 & 0.3 & 235.0 \\
\hline
\end{tabular}

modification was proposed in this paper. In the method proposed, the cross-section was analysed during computations (within each iteration loop). This allowed to eliminate the interpolation error due to the usage of exact values for the cross-section analysed. The updated GNCL method was implemented in the MATLAB in-house code.

\subsection{Materials}

The proposed method allows to use a nonlinear constitutive law of any material. In the examples, the nonlinear law of steel were used. In Table 1, the engineering parameters of steel used in the study are presented, where $E$ is a Young's modulus, $G$ is a shear modulus, $\nu$ is a Poisson's ratio and $f_{y}$ is a yield strength of steel.

In the examples analysed here, the steel was described by an elastic perfectly-plastic model:

$$
\sigma_{\text {red }}=\left\{E \varepsilon_{\text {red }}, \quad \text { for } \quad \varepsilon_{\text {red }}<\frac{f_{y}}{E}, \quad f_{y} \text { for } \quad \varepsilon_{\text {red }} \geq \frac{f_{y}}{E}\right\} .
$$

\section{EXAMPLES}

\subsection{Example 1}

In order to verify the proposed method, the simply supported beams of IPE300 steel member and lengths of $1.5 \mathrm{~m}$ and $2.4 \mathrm{~m}$ (beams of two lengths to obtain two different values of slenderness ratio) were modelled. The beams with a vertical displacement in the center of the span were loaded. The displacement control was used. The obtained forces from the GNCL method were compared with the reference model results. The beams in FE commercial software were divided into $5 \mathrm{~mm}$ long elements, thus 300 and 480 2-node linear beam elements were obtained for $1.5 \mathrm{~m}$ and $2.4 \mathrm{~m}$, respectively. In Figure 1, the static equilibrium paths for two beam lengths were shown.

In the beginning, the force increases linearly - the material is in the elastic phase. Later, the cross-section begins to plasticize as shown by the nonlinear shape of the plot. For beam of length of $1.5 \mathrm{~m}$, the difference between the proposed model and the reference model is $6.2 \%$, and for a length of $2.4 \mathrm{~m}$ it is $2.1 \%$.

The influence of the shear force on the load capacity of the cross-section was also analysed. For this purpose, the Bernoulli and Timoshenko theory were applied, and the proposed method was used. In Figure 2, the obtained static equilibrium paths are presented.

In Figure 2, the force obtained for the Bernoulli theory is greater than the force obtained for the Timoshenko theory. This is due to the fact that taking into account the shear strains causes a greater stiffness reduction, and thus the possibility of transferring a smaller force. The shorter the beam, the greater the influence of the shear force on the behaviour of the structure. In the analysed case, for the slenderness ratio of 5 (beam length $1.5 \mathrm{~m}$ ) the difference in load capacity is $6.5 \%$, and for the slenderness ratio of 8 (beam length $2.4 \mathrm{~m}$ ) it is only $2.2 \%$. 
a)

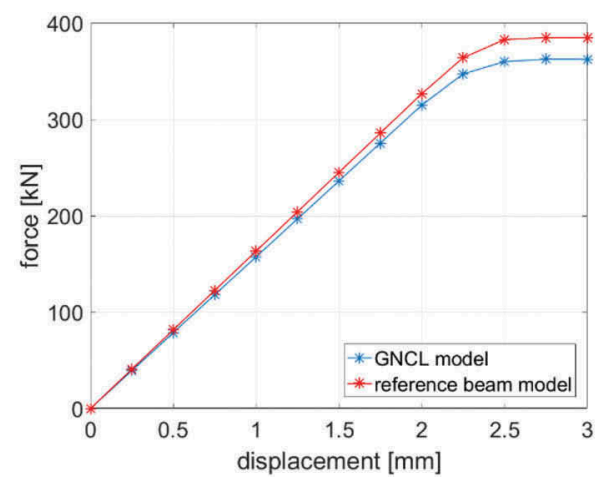

b)

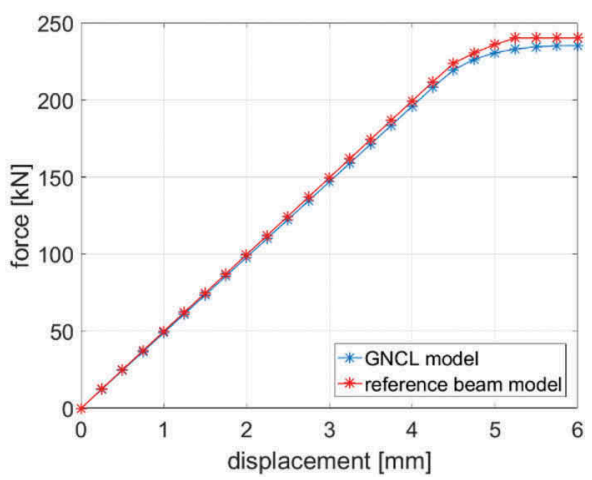

Figure 1. Force vs. displacement plots due to enforcing displacements in the middle of the IPE300 beams for their lengths of a) $1.5 \mathrm{~m}$ and b) $2.4 \mathrm{~m}$.

a)

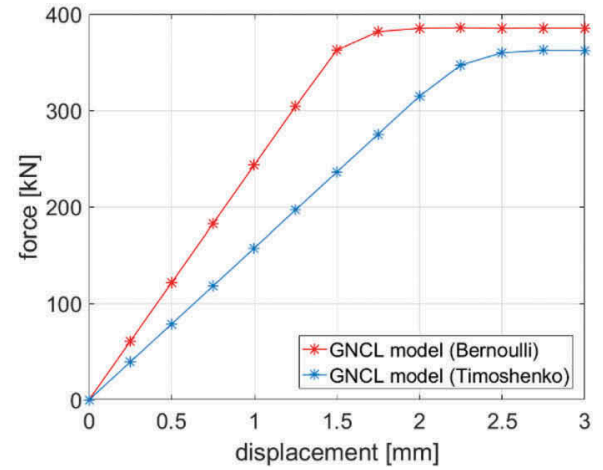

b)

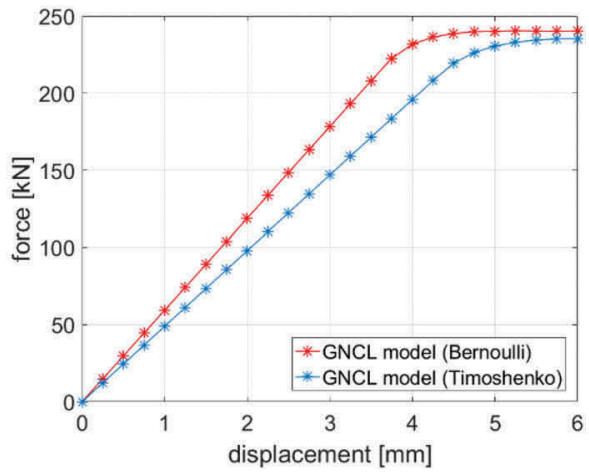

Figure 2. Force vs. displacement plots obtained for the Bernoulli and Timoshenko theories of the IPE300 beams for their lengths of a) $1.5 \mathrm{~m}$ and b) $2.4 \mathrm{~m}$.

\subsection{Example 2}

The influence of the material plasticization and shear force was also shown on the example of a single-nave frame with overhangs (cantilevers) loaded with a uniformly distributed load $Q=70.0 \mathrm{kN} / \mathrm{m}$ on the beam and concentrated forces $P=70 \mathrm{kN}$ on the ends of the cantilevers. The static scheme of the frame is shown in Figure 3. The stiffness reduction of the beam and cantilevers caused by plasticization of the material was computed according to GNCL method for Bernoulli theory and Timoshenko theory and was shown in Figure 4a and Figure $4 b$, respectively.

Comparing Figure $4 \mathrm{a}$ and Figure $4 \mathrm{~b}$ shows that taking into account the effect of the shear force causes a greater stiffness decrease. This is associated with an displacement increase. The maximum deflections in the middle of the horizontal element (point $\mathrm{C}$ ) and cantilever end (point A) for the Bernoulli theory are $4.29 \mathrm{~cm}$ and $1.07 \mathrm{~cm}$, respectively, and for the Timoshenko theory $9.75 \mathrm{~cm}$ and $1.23 \mathrm{~cm}$. Taking into account the influence of the shear force, the deflections in the middle of the horizontal element and at the cantilever end increased by $127.3 \%$ and $15.0 \%$, respectively. 


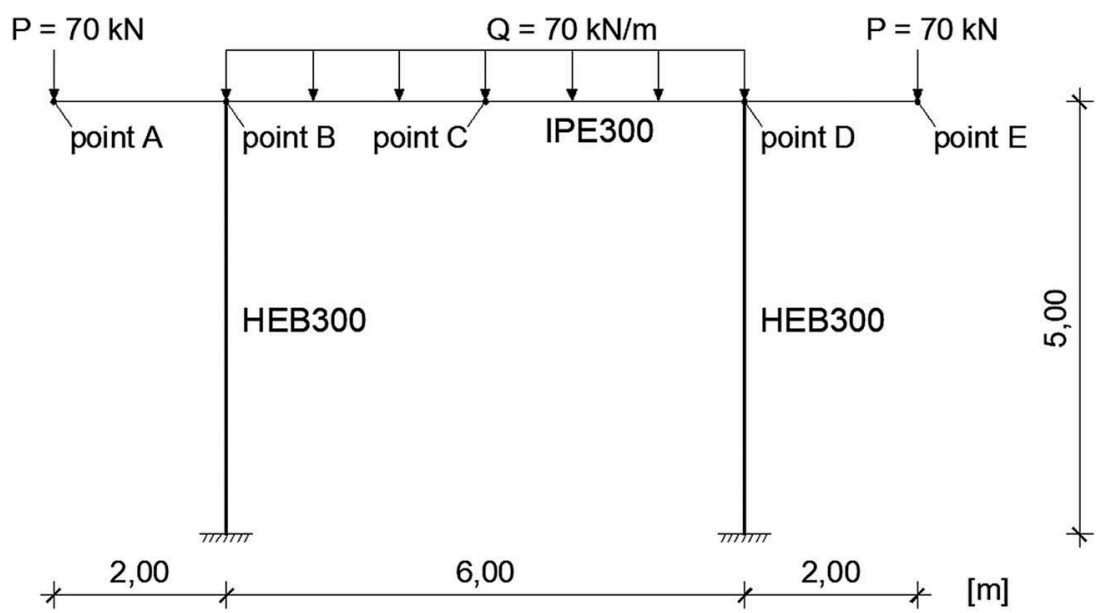

Figure 3. Static scheme of the Example 2.

a)

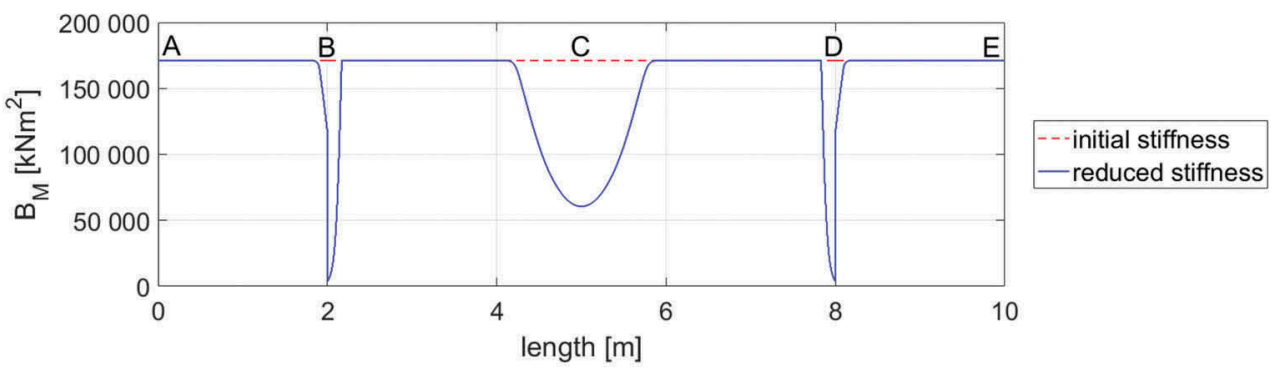

b)

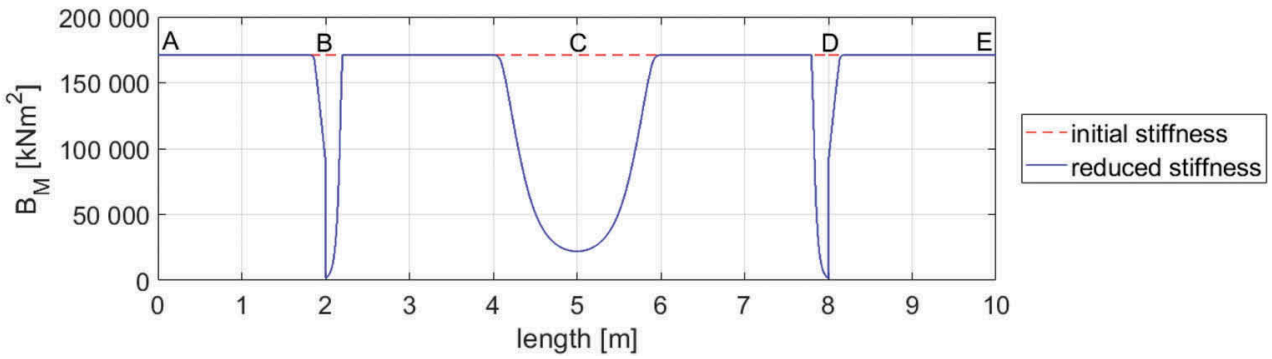

Figure 4. Reduction of bending stiffness $B_{M}$ of beam and cantilevers according to a) Bernoulli theory and b) Timoshenko theory.

\section{CONCLUSIONS}

The method of generalized nonlinear constitutive law presented in the paper extends the classical finite element method approach and seems to be promising tool for fast and accurate simulations of complex structures. Especially in cases, in which the cross-section is multi-material, compound of many subsections and the nonlinear properties of material should be included. Here, the classical GNCL method was extended with Timoshenko theory in order to apply the method in a less slender structures. This utility is not available in the classical finite element method softwares for structure engineers. In this paper, the method was described and shown on numerical examples. The results were compared with 
the commercial software for simply supported beam, with a good agreement of the displacements. Also, the Bernoulli vs. Timoshenko theory was confronted in the example of single-nave frame with overhangs, in which including a shear effect had a big influence on the displacement obtained.

\section{REFERENCES}

Grzeszykowski, B. \& Szmigiera, E. 2019. Nonlinear longitudinal shear distribution in steel-concrete composite beams. Archives of Civil Engineering 65(1): 65-82.

Łodygowski, T. 1982. Geometrycznie nieliniowa analiza sztywno-plastycznych i sprężysto-plastycznych belek i ram płaskich. Warsaw.

Łodygowski, T. \& Szumigała, M. 1992. Engineering models for numerical analysis of composite bending members. Mechanics of Structures and Machines 20: 363-380.

Mrówczyński, D., Gajewski, T. \& Garbowski, T. 2021. Application of the generalized nonlinear constitutive law in 2D shear flexible beam structures. Archives of Civil Engineering (accepted for publication).

Rotter, J. \& Ansourian, P. 1978. Cross-section behaviour and ductility in composite beams.

Szumigała, M. 2007. Zespolone stalowo-betonowe konstrukcje szkieletowe pod obciążeniem doraźnym. Wydawnictwo Politechniki Poznańskiej. Poland. 